\title{
Clinical Profile and Sensitivity Pattern of Salmonella Serotypes in Children: A Hospital Based Study
}

\author{
Joshi BG ${ }^{1}$, Keyal K², Pandey R $^{3}$, Shrestha BM $^{4}$
}

${ }^{1}$ Dr. Binita G. Joshi, MBBS, MD, Registrar, ${ }^{2}$ Dr. Kabita Keyal, MBBS, MD, Registrar, ${ }^{3}$ Dr. Rajesh Pandey, MBBS, Medical Officer, ${ }^{4} \mathrm{Dr}$. Binod Man Shrestha, MBBS, DCH, MD, Professor in Paediatrics (NAMS), 1, 2, ${ }^{3}$ Department of Paediatrics, Civil Service Hospital, ${ }^{4}$ Department of Paediatrics, Kanti Children's Hospital.

Address for correspondence: Dr. Binita G. Joshi, E-mail: binitasay@yahoo.com

\begin{abstract}
Introduction: Enteric fever is a systemic infection caused by the bacteria, Salmonella enterica serovar Typhi (S.typhi) and Salmonella enterica serovara Paratyphi (S. paratyphi A, B and C). Most of the burden of the disease is limited to the developing world and the disease still has the issues like wide spectrum of clinical presentation and multidrug resistance. Objectives: This study was done to analyze the clinical profile and antibiotic sensitivity pattern in the cases of culture positive enteric fever. Methods: A prospective cross-sectional study was conducted in Civil Service Hospital from February 2010 to January 2011 in the paediatric population in the age group of 2 to 14 years. Children with Salmonella species isolated in blood culture were included in the study. Results: Out of the 40 children with culture positive enteric fever, male to female ratio was 1.3:1 with common age group between 11-14 years. S typhi was isolated in 25 cases while S. paratyphi in 15 cases. Clinical features of S. typhi and S. paratyphi were indistinguishable. Both S.typhi and S. paratyphi were found to be $100 \%$ sensitive to drugs like Ceftriaxone, Cefotaxime, Cefixime and Chloramphenicol. Sensitivity to Ofloxacin was $100 \%$ in S. paratyphi and $92 \%$ in S.typhi. Similarly sensitivity of Azithromycin was $92 \%$ and $93 \%$ for S.typhi and S. paratyphi respectively. Conclusion: Salmonella serotype is still $100 \%$ sensitive to third generation cephalosporin. Some percentage of resistance is seen with Ofloxacin in S. typhi and with Azithromycin in both S.typhi and S. paratyphi.
\end{abstract}

Key words: Enteric fever, S.typhi, S.paratyphi, Sensitivity

Introduction
- nteric fever is a systemic infection caused by
the bacteria Salmonella enterica serovar Typhi (S.typhi) and Salmonella enterica serovara Paratyphi (S. paratyphi A, B and C). Because of the provision of clean water and good sewage system, it is a sporadic disease in developed countries and occurs mainly in travellers returning from endemic regions. Today, most of the burden of the disease is limited to the developing countries where standards of hygiene and sanitation remain poor ${ }^{1}$.

The global estimate of incidence of enteric fever caused by $S$. typhi is over 21 million causing 700,000 deaths each year and more than 5 million new infections are caused by S. paratyphi $A^{2,3}$. It is one of the major public health problems in Nepal, particularly in Kathmandu and other urban areas ${ }^{4}$. Chloramphenicol became the standard antibiotic since its introduction in 1948. Its resistance occurred within two years after its introduction, but Chloramphenicol - resistant typhoid fever became a major problem in 1972 when outbreaks occurred in Asia and Latin America ${ }^{1,5,6}$. Later in late 1980s, S. typhi developed multi drug resistance to Chloramphenicol, Trimethoprim, Ampicillin and Sulfamethoxazole which were then used as first-line drugs, leading to outbreaks in Asia and Africa ${ }^{7,8,9,10}$. Fluoroquinolones were very effective in early 1990s, but emergence of resistance to these drugs have occurred ${ }^{11}$. Also sporadic reports of high level of resistance to Ceftriaxone in S.typhi and S.paratyphi have been seen and the relapse rate is $3-6 \%$ with this drug ${ }^{1,12}$. Cefixime though, effective and cheaper oral option for the treatment of multidrug- 
resistant cases, experience with this drug is less ${ }^{13}$. A short course of 5-7 days of treatment with Azithromycin is enough in uncomplicated typhoid fever, which has a relapse rate of less than $3 \%$ as compared to Ofloxacin where 7-10 days of treatment is required. Short course of treatment with Ofloxacin (less than 7 days) has higher incidence of treatment failure ${ }^{14,15}$.

Enteric fever still has issues like wide spectrum of clinical presentation and complex mode of treatment ${ }^{12}$. Hence this paper describes clinical profile and antibiogram of S.typhi and S. paratyphi.

\section{Materials and methods}

A prospective cross-sectional study was conducted in Civil service Hospital from February 2010 to January 2011. All the patients between the ages of 2 years to 14 years presenting to outpatient department who were suspected to have enteric fever had complete blood count and blood culture and sensitivity done. Those cases with Salmonella species isolated in culture were included while clinically diagnosed enteric fever was excluded from the study.

All blood samples were grown in Mac Conkey's agar for at least 96 hours and Mueller-Hinton agar with Kirky Bauer disc diffusion was used for sensitivity of culture.

\section{Results}

The study revealed total of 40 cases of culture positive enteric fever. Out of 40 children, 23(57.5\%) were male and $17(42.5 \%)$ were female. According to age wise distribution, 2-5 years were $20 \%, 6-10$ years were $32.5 \%$ and $11-14$ years were $47.5 \%$. Of the 8 patients $(20 \%)$ in the age group of $2-5$ years, male to female distribution was equal.Thirteen patients were

in the age group of 6-10 years with male: female ratio being $0.8: 1$. Of 19 patients in the age group of $11-14$ years; male: female ratio was 2.1:1. (Table 1).

Table 1: Age and sex distribution

\begin{tabular}{|l|c|c|c|c|c|c|}
\hline \multirow{2}{*}{$\begin{array}{c}\text { Age Group } \\
\text { (year) }\end{array}$} & \multicolumn{2}{|c|}{ Male } & \multicolumn{2}{c|}{ Female } & \multicolumn{2}{c|}{ Total } \\
\cline { 2 - 7 } & $\mathbf{n}$ & $\mathbf{\%}$ & $\mathbf{n}$ & $\mathbf{\%}$ & $\mathbf{n}$ & $\%$ \\
\hline $2-5$ & 4 & 50 & 4 & 50 & 8 & 20 \\
\hline $6-10$ & 6 & 46.1 & 7 & 53.8 & 13 & 32.5 \\
\hline $11-14$ & 13 & 68.5 & 6 & 31.5 & 19 & 47.5 \\
\hline \multicolumn{1}{|c|}{ Total } & $\mathbf{2 3}$ & $\mathbf{5 7 . 5}$ & $\mathbf{1 7}$ & $\mathbf{4 2 . 5}$ & $\mathbf{4 0}$ & $\mathbf{1 0 0}$ \\
\hline
\end{tabular}

The occurrence of the disease was higher during summer and rainy season (Fig. 1). Out of 40 cases, 25(62.5\%) were S. typhi and $15(37.5 \%)$ were S. paratyphi A.

All patients had fever. Headache, abdominal pain and vomiting were the most common associated symptoms seen in $52.5 \%, 22.5 \%$ and $20 \%$ respectively. Six patients had constipation and four patients had diarrhea (Table 2). On examination, hepatosplenomegaly was seen in three patients while splenomegaly was seen in five patients. $92.5 \%$ had the WBC count within the normal range (4000-11000) while $7.5 \%$ patients had leucopenia. No patient had leukocytosis

Table 2: Symptoms in culture positive patients.

\begin{tabular}{|l|c|c|}
\hline \multicolumn{1}{|c|}{ Symptoms } & No. of patients & Percentage \\
\hline Fever & 40 & 100 \\
\hline Headache & 21 & 52.5 \\
\hline Abdominal pain & 9 & 22.5 \\
\hline Vomiting & 8 & 20 \\
\hline Constipation & 6 & 15 \\
\hline Diarrhoea & 4 & 10 \\
\hline
\end{tabular}

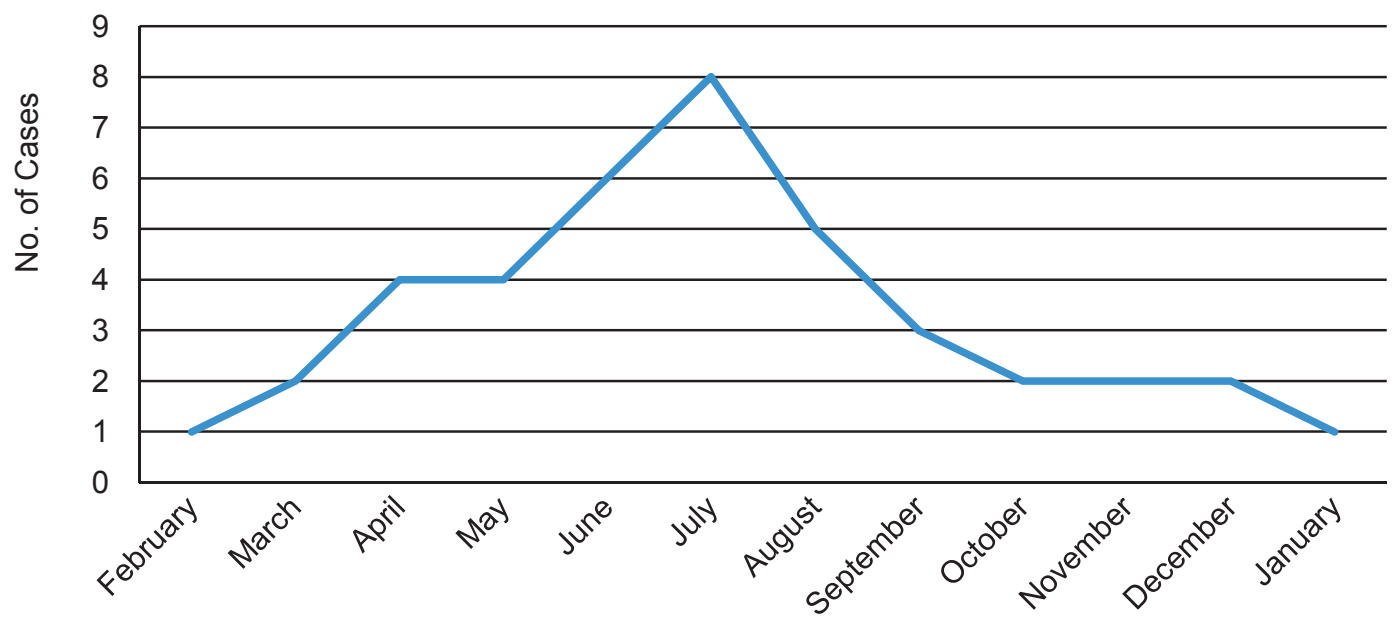

Fig 1: Seasonal Incidence 
S.typhi was found to be most sensitive to Ceftriaxone, Cefotaxime, Cefixime, Chloramphenicol and Cotrimoxazole (100\%) followed by Ofloxacin and Azithromycin (92\%) and Ciprofloxacin (88\%). It was least sensitive to Ampicillin (76\%) and Nalidixic acid (44\%) Table 3. S. paratyphi A was found to be most sensitive to Ceftriaxone, Cefotaxime ${ }_{2}$ Cefixime, Ciprofloxacin, Ofloxacin, Chloramphenicol and Cotrimoxazole (100\%) followed by Azithromycin (93.3\%), Ciprofloxacin (86.6\%) and Ampicillin (73.3\%). It was also least sensitive to Nalidixic acid (40\%) (Table 4).

Table 3: Antibiotic Sensitivity pattern of S.typhi $(n=25)$

\begin{tabular}{|l|c|c|}
\hline \multicolumn{1}{|c|}{ Drugs } & Number & $\begin{array}{c}\text { Percentage } \\
\text { of Sensitivity }\end{array}$ \\
\hline Chloramphenicol & 25 & 100 \\
\hline Cotrimoxazole & 25 & 100 \\
\hline Ceftriaxone & 25 & 100 \\
\hline Cefotaxime & 25 & 100 \\
\hline Cefixime & 25 & 100 \\
\hline Ofloxacin & 23 & 92 \\
\hline Azithromycin & 23 & 92 \\
\hline Ciprofloxacin & 22 & 88 \\
\hline Ampicillin & 19 & 76 \\
\hline Nalidixic acid & 11 & 44 \\
\hline
\end{tabular}

Table 4: Antibiotic Sensitivity pattern of S.paratyphi $(n=15)$

\begin{tabular}{|l|c|c|}
\hline Drugs & Number & $\begin{array}{c}\text { Percentage } \\
\text { of Sensitivity }\end{array}$ \\
\hline Cefixime & 15 & 100 \\
\hline Ceftriaxone & 15 & 100 \\
\hline Cotrimoxazole & 15 & 100 \\
\hline Chloramphenicol & 15 & 100 \\
\hline Cefotaxime & 15 & 100 \\
\hline Ofloxacin & 15 & 100 \\
\hline Azithromycin & 14 & 93.3 \\
\hline Ciprofloxacin & 13 & 86.6 \\
\hline Ampicillin & 11 & 73.3 \\
\hline Nalidixic acid & 6 & 40 \\
\hline
\end{tabular}

\section{Discussion}

Enteric fever is one of the common causes of febrile illness and is the major reason for seeking health service by general population ${ }^{16}$.

In this study, the most common age group affected was $11-14$ years $(47.5 \%)$. This result is much different from the study of Prajapati et al where result showed that common age group was $1-5$ years $^{17}$. Out of 40 children, males had higher incidence of disease (male to female ratio of 1.3:1). The study done by Ansari et $\mathrm{al}^{18}$ and Bhattarai et $\mathrm{al}^{19}$ showed similar results. There was clustering of cases of both S.typhi and S. paratyphi during summer and rainy seasons which is similar to the study done by Karkey $A^{3}$. This study also showed that fever was present in all the patients followed by headache, abdominal pain and vomiting which is similar to other studies ${ }^{16,20,21}$.

Clinical symptoms of $S$. typhi and S. paratyphi $A$ were indistinguishable in this study, which is similar to the study done by Karkey $\mathrm{A}^{4}$. The incidence of S.typhi and $S$. paratyphi $A$ in this study was similar to findings reported by Karkey et $\mathrm{al}^{3}$ and Jog et $\mathrm{al}^{12}$. The antibiotic sensitivity pattern was also not much different from other studies $^{16,19}$. In our study $100 \%$ sensitivity was seen with Ceftriaxone, Cefotaxime, Cefixime, Chloramphenicol and Cotrimoxazole. Sensitivity to Ofloxacin was $100 \%$ in S. paratyphi and $92 \%$ in S.typhi. Azithromycin resistance is documented in some percentage of Salmonella serotypes in our study which is different from the study done by Mishra et al where result shared $100 \%$ sensitivity to Azithromycin ${ }^{22}$. This could be due to larger sample size and mostly adult population. Most of the patients had normal leucocyte count which was similar to other literatures ${ }^{12,19,21}$.

\section{Acknowledgement: None \\ Funding: None \\ Conflicting Interests: None \\ Permission from IRB: Yes}

\section{Conclusion}

Salmonella serotype is still $100 \%$ sensitive to third generation cephalosporin. Some percentage of resistance is seen with Ofloxacin in S. typhi and with Azithromycin in both S.typhi and S. paratyphi. In the endemic region like ours, appropriate antibiotic should be chosen as indicated by sensitivity pattern to prevent the emergence of resistance to common drugs.

\section{References}

1. Parry CM, Hien TT, Dougan G, White NJ, et al. (2002) Typhoid fever. N Eng J Med 347:1770-1782.

2. Crump JA, Luby S P, Mintz ED (2004) The global burden of typhoid fever. Bull World Health Organ 82:346-353.

3. Karkey A, Arjyal A, Anders KL, Boni M.F, Dongol S et al. www.plosone.org Nov 2010;S(11) e 13988.

4. Karkey A, Arjyal A, Basnyat B, Baker S. Kathmandu, Nepal: still an enteric fever capital of the world. $J$ Infect Developing Countries 2008;2(6):461-461. 
5. Bhatia JK, Mathur AD, Arora MM Reemergence of Chloramphenicol sensitivity in enteric fever. Med $J$ Armed Forces India 2007;63:212-14.

6. Olarte J, Galindo E. S typhi resistant to chloramphenicol, ampicillin and other antimicrobial agents: strains isolated in extensive typhoid fever epidemic in Mexico. Antimicrob Agents Chemother 1973;4:597-601.

7. Mirza SH, Beeching NJ, Hart CA. Multi-drug resistant typhoid: a global problem. J Med Microbiol 1996;44:317-9.

8. Threlfall EJ, Ward LR, Rowe B, et al. Widespread occurrence of multiple drug -resistant Salmonella typhi in India. Eur J Clin Microbiol Infect Dis 1992;11:990-3.

9. Bhutta ZA. Impact of age and drug resistance on mortality in typhoid fever. Arch Dis Child $1996 ; 75: 214-7$

10. Kariuki S, Gilks C, Revathi G, Hart CA. Genotypic analysis of multidrug resistant Salmonella enterica serovar typhi, Kenya. Emerg Infect Dis 2000;6:64951.

11. Malla S, Kansakar P, Serichantalergs O, Rahman M, Basnet S. Epidemiology of typhoid and paratyphoid fever in Kathmandu: two years study and trends of antimicrobial resistance. JNMA 2005;4(157):18-22.

12. Jog S, Soman R, Singhal T, Rodrigues C, Mehta A,et al. Enteric Fever in Mumbai -Clinical Profile, Sensitivity pattern and Response to Antimicrobials. JAPI 2008;56.

13. Memon IA, Billoo AG, Memon HI. Cefixime: an oral option for the treatment of multidrug resistant enteric fever in children. South Med J. 1997;90(12):12041207.
14. Frenek R W Jr, Mansour A, Nakhla I, Sultan $Y$ et al. Short course azithromycin for the treatment of uncomplicated typhoid fever in children and adolescents. Clin infect Dis 2004;38:951-7.

15. Wain J, Hoa NT, Chinh N T, et al. Quinoloneresistant Salmonella typhi in Vietnam: molecular basis of resistance and clinical response to treatment. Clin Infect Dis 1997;25:1404-1410.

16. KC Mathura, Chaudhary D, Simkhada R, Pradhan $M$, Shrestha $G$ et al. Study of clinical profile and antibiotic sensitivity pattern in culture positive typhoid fever. KUMJ 2005;3(4):376-379.

17. Prajapati B, Rai GK, Rai SK, Upreti HC, et al. Prevalence of Salmonella typhi and paratyphi infection in Children: a hospital based study. Nepal Med Coll J 2008;10(4):238-241.

18. Ansari I, Adhikari N, Pande R, Dangal MM et al. Enteric fever: is ciprofloxacin failing? J Nepal Pediatr Soc 2002;20:6-16.

19. Bhattarai PM, Bista KP, Dhakwa JR, et al. A clinical profile of enteric fever at Kanti Children's Hospital $J$ Nepal Paediatr Soc 2003;21:50-3.

20. Neopane A, Singh SB, Bhatta R, Dhital B, et al. Changing spectrum of antibiotic sensitivity in enteric fever. KUMJ 2008;6(1):12-15.

21. Ramaswamy G, Janakiraman L, Thiruvengadam $V$, et al. Profile of Typhoid Fever in Children from Tertiary Care Hospital in Chennai - South India. Indian J Pediatr 2010;77:1089-1092.

22. Mishra SK, Sah JP, Shrestha R, Lakhey M. Emergence of Nalidixic acid resistant Salmonella : a confounding scene in antibiotic armamentarium. $J$ Nepal Med Lab Sci 2008;9(1):61-6

\section{How to cite this article ?}

Joshi BG, Keyal K, Pandey R, Shrestha BM. Clinical Profile and Sensitivity Pattern of Salmonella Serotypes in Children: A Hospital Based Study. J Nepal Paediatr Soc 2011;31(3):180-183. 